\title{
Clarity on Cannabinoid-Based Products in Medicine
}

Authors:

Disclosure:

Acknowledgements:

Support:

Received:

Accepted:

Keywords:

Citation:
Rafael Maldonado,, Diego Centonze, ${ }^{2,3}$ Kirsten Muller-Vahl ${ }^{4}$

1. Professor of Pharmacology, University Pompeu Fabra, Barcelona, Spain

2. Professor of Neurology, Tor Vergata University, Rome, Italy

3. Director of the Neurology Unit, IRCSS Istituto Neurologico Mediterraneo Neuromed, Pozzilli, Italy

4. Professor of Psychiatry, Department of Psychiatry, Socialpsychiatry and Psychotherapy, Hannover Medical School, Germany

The authors have declared no related conflicts of interest.

Writing assistance was provided by Havas Lynx.

This publication was funded by Almirall SA.

15.03 .21

7.05.21

Cannabidiol (CBD), cannabinoids, cannabis, herbal, marijuana, nabiximols, sativex, tetrahydrocannabinol (THC).

EMJ Neurol. 2021;9[Suppl 3]:2-20; DOI 10.33590/emjneurol/21-07-suppl-3

\section{Abstract}

The perception of cannabis in society has changed over the last decades, leading to an increasing permissiveness about its use mainly across Western countries. This has happened in parallel to the growing study of the possible role of cannabinoid-based products in medicine. The cannabis plant contents comprise more than one hundred different cannabinoids, each binding differently to numerous human body targets. This cannabinoids administration, either isolated, combining some of them, or as a full plant extract can produce many different risk-benefit effects in humans depending on the product composition. Moreover, we have seen the appearance of synthetic cannabinoids. As expected, doses and different routes of administration introduce further variability. Cannabinoidbased pharmaceutical products authorised for medicinal use after comprehensive research and with approval by regulatory medicines agencies, such as the European Medicines Agency (EMA) and U.S. Food and Drug Administration (FDA), should be distinguished from cannabinoid-based products (whether standardised or not) that aimed for medicinal use but lack submitted efficacy, tolerability, and safety scientific evidence for regulatory approval. Distribution of some of the latter products are still allowed in certain geographical areas. There are also cannabinoid products used mainly recreationally or as food supplements and ruled separately. In a detailed white paper, this review describes the present situation, depicting the societal and medical state of the art, collecting the facts-based risk-benefit features of already available cannabinoid-based products, and also the future possibilities in medicine, which can be vast if proper research is developed.

Chapter 1: Introduction

Chapter 2: Perception of cannabis in society

Chapter 3: The growing role of cannabinoid-based products in medicine

Chapter 4: Differentiating approved cannabinoid-based medicines from other cannabis-based products 
Chapter 5: Adverse events, including psychosis risk, with cannabis-based products

Chapter 6: Conclusion

\section{CHAPTER 1: INTRODUCTION}

This document aims to provide an overview of the clinical and regulatory challenges faced in the use of cannabinoid-based products in medicine, without becoming a comprehensive humanity review of the literature on the medical possibilities of cannabinoids.

\section{The Use of Cannabis Throughout History}

The use of herbal cannabis varieties by humans is not a new concept. Herbal cannabis was one of the first plants to be cultivated by humans and has since been adapted to meet a number of human needs, including, but not limited to, technical, nutritional, recreational, and medicinal." As early as 4000 BC, cannabis plants were regarded as one of the five core grains in China and farmed as a major food crop. $^{2}$ Later, in 2737 BC, can be found the first recorded use of herbal cannabis for medicinal purposes, aiming to combat a variety of ailments, including gout, rheumatism, and malaria. ${ }^{2}$ Other properties later claimed included benefits in treating epilepsy, anxiety, bronchitis, rabies, toothache, and inflammation. In the Roman Empire, females also used cannabis to alleviate labour pains. ${ }^{2}$ Possible routes of administration at the time were not unlike those used today, including smoking or mixing the seeds with alcohol. 3,4

It was not until 1839 that the therapeutic uses of herbal cannabis derivatives were introduced to Western medicine by an Irish doctor, William O'Shaughnessy. ${ }^{2}$ This led to the widespread sale of cannabis extracts in the late 1800s, mostly pursuing the treatment of stomach complaints. ${ }^{2}$ Later, in the 1900s, the cannabis plant was also used to treat nausea, rheumatism, and labour pain and was available over the counter in preparations such as tinctures called 'Piso's cure' and 'one-day cough cure'.

As well as its apparent benefits, ancient producers of cannabis were also aware of the psychoactive properties of the cannabis plant. Indeed, there are reports that they may have cultivated specific varieties of the plant to produce higher levels of its psychoactive ingredient, tetrahydrocannabinol (THC), for use during religious ceremonies and for potential healing practices. ${ }^{5}$ Despite this interest in the psychoactive properties of cannabis, the THC compound itself was not isolated until 1964. These psychoactive side effects are also alluded to in early descriptions of the preparations and, like today, seemed to divide opinion with references to being both a 'poison' 6 and a 'joy giver'. ${ }^{2}$ Cannabidiol (CBD) and other cannabinoid molecules were isolated from the plant in the following years, each of them with different properties.

Despite the positive perception of herbal cannabis usefulness in past centuries, the start of the $20^{\text {th }}$ century saw its progressive scheduling as an abuse-risk substance by most of the developed nations. Eventually, the United Nations (UN) issued the single convention on narcotic drugs, detailed later by the World Health Organization (WHO), scheduling the cannabis plant and its related derivatives (the flowering or fruiting tops of the plant and the separated resin, crude or purified, as obtained from the plant), classifying them under Schedule 1 of Controlled Substances (WHO substances under international control). These tight legal restrictions initially limited further research into the medicinal properties of the plant and its derivatives. ${ }^{2,7}$ More recently, however, after clinical research, certain cannabinoid-based medicines have received regulatory authorisation in a number of countries, including synthetic forms of THC and different pharmaceutical preparations of THC and CBD, following rigorous clinical evaluation. In other instances, restrictions on medicinal use of cannabis and its derivatives (without specific regulatory approval) have been reviewed in some countries and, in some cases, relaxed. For example, in 2017, Germany introduced new legislation permitting the use of cannabis derivatives for medicinal purposes in the absence of the EMA regulatory label under certain conditions. Since this change, Germany's medicinal cannabis market has become one of the most robust in Europe. ${ }^{8,9}$ Similarly, in 
November 2018, unlicensed cannabis-based products in the UK were re-classified from Schedule 1 to Schedule 2, meaning they could be prescribed for the first time. ${ }^{7}$

\section{Increasing General Interest}

The interest in the cannabis plant, and its derived products for medicinal use, has seen a considerable increase over the last few decades. From 1990 to 2019, PubMed reflected a sevenfold increase, from 101 to 762, in the number of publications per year about THC, the key plant cannabinoid; scientific publications mentioning cannabis in PubMed grew 30-fold, from 80 to 2,408 , between the same years. In a longitudinal study in the USA, 6.4 million Google searches for the molecule $\mathrm{CBD}$, one of the most relevant of over 160 different cannabinoid molecules in the cannabis plant, ${ }^{7}$ were made during April 2019.10 Moreover, Google search data also suggested that interest in these products had increased by as much as $160.4 \%$ in 2018 , compared to the previous year." Considering non-medicinal aimed uses, celebrity endorsements of cannabis-derived products, as well as a $60 \%$ global increase in recreational herbal cannabis use over the last decade, indicate a greater awareness of these products in society than ever before. ${ }^{12}$

\section{The Cannabis Plant: Properties and Cultivation}

Since 1961, European law has defined the cannabis plant as any plant of the genus 'Cannabis'. ${ }^{9}$ There are two main subspecies of the cannabis plant, both of which are native to India; Cannabis sativa is believed to have originated in a region north of the Himalayas, ${ }^{13}$ while the Cannabis indica variety may be traced back to the Hindu Kush mountain range along the Afghan-Pakistani border. ${ }^{14}$ The Cannabis indica subspecies has historically been considered to have higher concentrations of CBD than the Cannabis sativa subspecies, which reportedly had a higher THC content. ${ }^{15}$ However, years of crossbreeding these subspecies has resulted in varying $\mathrm{THC}$ and $\mathrm{CBD}$ concentrations within varieties. ${ }^{16}$ The cannabis plant usually blooms one of two types of flower referred to as either 'male' or 'female', with some plants producing both types of flower. 'Hashish', a typical recreational cannabis product, is made from the resin of these cannabis flowers. Hemp products are derived from the two most fibrous parts of the cannabis plant stalk: the hurd and the bast. ${ }^{13}$ The bast provides fibres, also called hemp, that may be used to make various products such as canvases and, historically, were a popular choice for ship sails. ${ }^{13}$ The hurd can be used to produce a pulp that may be used in paper and paints, or seeds for food. ${ }^{13}$

There are more than 160 specific, naturally occurring cannabinoid compounds that can be derived from cannabis plants. ${ }^{17}$ Alongside these phytocannabinoids, the plant contains hundreds of other compounds (e.g., terpenes, phenolic compounds, and lignans). The compounds that fall under the umbrella term of 'phytocannabinoids' do so due to their origin. These are based on their derivation from a common C21 precursor, cannabigerolic acid, or its C19 analogue, cannabigerovaric acid, the predominate phytocannabinoid precursors formed through the reaction of geranyl pyrophosphate with olivetolic and divarinic acid, respectively. Those that have been studied the most display abilities to bind to human cannabinoid receptors. Cannabinoid receptors are distributed in both the central nervous system and throughout the body, where endogenous human endocannabinoid molecules such as anandamide (AEA) or 2-arachidonoyl-glycerol (2-AG) act to modulate different endogenous functioning pathways. However, while central cannabinoid $\mathrm{CB}_{1}$ receptors are particularly located in the central nervous system (CNS), cannabinoid $\mathrm{CB}_{2}$ receptors are mainly located on peripheral immune cells. ${ }^{18}$ Phytocannabinoids can mimic the binding of endocannabinoids to these receptors. ${ }^{18}$ Phytocannabinoids may be distributed among 10 main subclasses including $\triangle 9$ - and $\triangle 8-T H C, C B D$, cannabigerol, cannabinol, cannabinodiol, cannabielsoin, cannabicyclol, cannabitriol, and miscellaneous. ${ }^{17}$

\section{Cannabis-Derived Products: Beyond Medicinal Use}

As cannabis has become more widely used among the public, the isolation of its active compounds, and the use of these to create completely new products, is an area of consumerism that has become increasingly commonplace. One of the most well-known products is CBD oil sold as a food supplement, which is used by many to aid their wellness. In 
contrast, food supplements are not intended to have a therapeutic effect or to treat any disease. Customers purchasing CBD oil are usually searching for a way to help their health without experiencing the intoxicating sideeffects that would be present with the use of the whole plant. ${ }^{19}$ In recent years, this has become a popular over-the-counter remedy of choice for a wide range of ailments, ${ }^{20}$ often in the absence of scientific assessment and recognition from health authorities. ${ }^{20}$

As well as using the isolated compounds directly, many consumer areas are beginning to incorporate cannabinoids into their products. The apparent anti-inflammatory properties of CBD have led to them being used in beauty and skincare products and utilised as a key selling point for these items. A wide variety of products have been reported to include the beneficial therapeutic effects of $\mathrm{CBD}$, ranging from lip balms to bath bombs. Indeed, products that contain $\mathrm{CBD}$ are starting to be sold on popular beauty websites, such as the USA beauty company, Sephora (Paris, France). ${ }^{19}$

Increasingly, people are incorporating cannabis into their diet. A simple Google search for 'cooking with cannabis' generated over 35 million results, and $36 \%$ of adult Italians reported that they either had or would be willing to try drinks infused with cannabis. ${ }^{21}$ As a result of this, some companies are attempting to provide foodstuff with cannabis products already included. Within Europe, foods containing cannabinoid extracts or isolates are considered to be 'novel' and have been included in the novel food catalogue as of January 2019. ${ }^{22}$ However, a CBD food product cannot be created simply by adding CBD into the list of ingredients. In the UK, any food product containing CBD must be authorised as a novel CBD product before it can be brought to market. The cost of authorisation regarding both time and money can make this process difficult. ${ }^{23}$ The authorisation process takes 2 years and can cost upwards of 300,000 EUR.

\section{A Differentiation Challenge}

Given their extensive and varied uses throughout history, it seems reasonable that certain cannabis-derived products with appropriate composition and administration form can demonstrate and provide medicinal value.
However, there is a lot of variation across countries and territories in law enforcement and the way that available medicinal and recreational preparations of different compounds are manufactured, developed, and approved. This variation has led to the challenge of differentiating between available products and understanding their important differences from a regulatory, efficacy, and safety standpoint. There remains a misconception that all cannabinoids, independent of their type, dose, or route of administration, might cause similar effects (e.g., the belief that they all can be psychoactive as THC) ${ }^{24}$ Additionally, the variety of existing cannabis plants, alongside the considerable range of available cannabinoids within the plant (which can be combined at different doses), plus the synthetic products, highlights a complexity to these products that remains neglected, and potentially misunderstood, by the public. ${ }^{24}$ This white paper will explore the varied and often confusing terminology that surrounds cannabinoid use and the challenges this may bring. The authors will also discuss the differences between regulated and unregulated products within this space and explore how approved medicinal cannabinoidbased products can be differentiated from cannabinoid-based, non-medicinal products.

\section{CHAPTER 2: PERCEPTION OF CANNABIS IN SOCIETY}

\section{A Changing Image?}

The control of substances with abuse-risk is always a topic for debate in any society, and cannabis is no exception; the so-called 'war on drugs' has divided public opinion for years. Despite its extensive historical use for a variety of notable purposes, the Second Opium Convention of 1925 placed cannabis under international controls, still in place throughout Europe and the world today, ${ }^{25}$ and is arguably responsible for its negative reputation in the modern day (regardless of whether that reputation is warranted or unwarranted).

According to the $\mathrm{WHO}$, herbal cannabis is by far the most widely cultivated, trafficked, and abused recreational drug in the world, with an estimated $2.5 \%$ of the global population consuming cannabis in some form every 
year. ${ }^{26}$ Moreover, according to the International Narcotics Control Board (INCB), the illicit use of cannabis has increased considerably since 2000, such that estimates for production of cannabis have increased 120 -fold in less than 20 years, from 1.3 million tonnes in 2000 to nearly 160 million tonnes in 2017.27 As previously described, there are a number of ways in which cannabis and its derivatives may be consumed, either for recreational use or for legitimate medicinal purposes.

\section{Cannabis and its Associated Products: Varied Terminology}

When referring to cannabis and its related products, there is a wealth of variation and terminology. Importantly, available products range from unregulated mixtures primarily consumed recreationally, and formulations indicated for medicinal use (some with regulatory approval by medicines agencies after submission of clinical trials dossiers). When considering products that are intended to be used for medicinal purposes, independently of the regulatory approval differences, there exists a broad degree of variation in active ingredient concentration, doses, potency, and routes of administration. ${ }^{9}$ Indeed, levels of regulation and governance also vary between these products. For example, forms of 'raw' cannabis, magistral (prepared by pharmacies), and standardised preparations of the cannabis plant may be used for medicinal purposes in some countries. However, these have not been formally authorised by their medicines agencies for any specific indication and can include varying concentrations of THC, CBD, other cannabinoids, and further components. ${ }^{9}$ Conversely, there are pharmaceutical-grade preparations of cannabinoids (including their synthetic counterparts) that have received marketing authorisation for selected indications and must meet the same rigorous clinical evaluation as any other medicine. ${ }^{9}$ Understanding the different terminology can further help differentiate between these products. ${ }^{7}$ Table 1 provides a glossary of terms. ${ }^{718,28,29}$

Inconsistent terminology is reflected in publications and internet search practices of cannabis-based products. When looking for more information on certain cannabis-based products, consumers are seemingly conflicted in their search terms, with searches for 'medical cannabis', 'medical marijuana', 'cannabinoid',
'CBD oil', and 'hemp oil', all featuring as popular search items. ${ }^{30}$ Insights from Google search hits revealed that the most recent results are generated through searches for 'medical weed' and 'CBD'. Interestingly, more accurate terms such as 'medicinal cannabinoids' yielded the lowest hits upon searching. ${ }^{31}$ This varied lexicon likely reflects local market preferences as well as cultural perceptions and attitudes towards cannabis-based product use. Is there also existing confusion around how exactly we differentiate between approved cannabinoidbased medicines, unapproved medicinal cannabis-based products, and those products intended for recreational use and use as food supplements?

\section{"My opinion is that when you mention the} word 'cannabis', people just relate it to one, single concept. They don't differentiate recreational cannabis, unregulated cannabis products, or regulated cannabis products. The majority of the population don't know this difference." Rafael Maldonado

\section{Confusion in Regulation}

There is still variability in the way cannabisbased products are regulated and used across territories, which, in turn, has the potential to cause confusion within society. As previously commented regarding $\mathrm{CBD}$ use as a food supplement and noted by Orrin Devinsky, director of the NYU Langone Comprehensive Epilepsy Centre, New York, USA: "In New York City, you can go to a latte shop and get a CBD product, but if I want to do a [CBD] clinical trial, I've got to get a 2,000-pound safe and go through 6 months of paperwork and licensing." 32

Another example is that while CBD has been deregulated in the USA, if it is sourced from hemp, it is still illegal in the USA to add CBD or hemp extract to food products. Therefore, in the USA, a product containing CBD may be sold in an establishment that sells food, but it is illegal to sell food products containing CBD.

Additionally, there is considerable global variation in the legality and regulation surrounding both the recreational and medicinal use of cannabisbased products. In March 2019, the WHO made recommendations to change the scheduling of cannabis-based products. 
Table 1: Cannabis and its associated products; a varied lexicon.

\begin{tabular}{|c|c|}
\hline Term & Definition \\
\hline \multicolumn{2}{|l|}{ Cannabinoids } \\
\hline Endocannabinoid & Also referred to as endogenous human cannabinoids. Include AEA and 2-AG, among others. \\
\hline Phytocannabinoid & $\begin{array}{l}\text { Cannabinoids found within the cannabis plant. Include THC and CBD. Also referred to as } \\
\text { exogenous cannabinoids as they bind to the human endocannabinoid receptors. }\end{array}$ \\
\hline $\begin{array}{l}\text { Synthetic } \\
\text { cannabinoid }\end{array}$ & $\begin{array}{l}\text { Cannabinoid-like molecules that are synthesised but aim to bind to endocannabinoid receptors. } \\
\text { They can be classified also as exogenous cannabinoids, together with the natural origin } \\
\text { phytocannabinoids. e.g., synthetic THC or nabilone (synthetic THC analogue). }\end{array}$ \\
\hline \multicolumn{2}{|l|}{ The plant } \\
\hline $\begin{array}{l}\text { Cannabis (whole } \\
\text { plant) }\end{array}$ & $\begin{array}{l}\text { The term 'cannabis' refers to a genus or family of plants, Cannabis sativa. These plants may also } \\
\text { be referred to as 'marijuana' or 'hemp' plants. There are a number of different varieties. }\end{array}$ \\
\hline Cannabinoid & $\begin{array}{l}\text { A compound that interacts with the endocannabinoid system. THC and CBD are both examples } \\
\text { of plant cannabinoids. }\end{array}$ \\
\hline THC & $\begin{array}{l}\text { Usually } \triangle 9-\mathrm{THC} \text { is meant when the term THC is used. It is the most psychoactive cannabinoid } \\
\text { of the cannabis plant that may be used as a pure drug or as part of medicinal cannabinoid } \\
\text { products. THC can be synthetised, instead of being extracted from the plant (then called by the } \\
\text { INN, dronabinol). } \triangle 8-\mathrm{THC} \text { is a degradation product of } \triangle 9-\mathrm{THC} \text { with different properties. }\end{array}$ \\
\hline CBD & $\begin{array}{l}\text { CBD is the second most important cannabinoid in the cannabis plant. It is used alone or as } \\
\text { part of medicinal cannabinoid products and does not carry the same psychoactive effects } \\
\text { as associated with THC. CBD is available not only as a medical product, but also as a food } \\
\text { supplement. }\end{array}$ \\
\hline \multicolumn{2}{|c|}{ Cannabinoid-based products in medicine } \\
\hline $\begin{array}{l}\text { Unapproved by } \\
\text { medicines agencies } \\
\text { cannabinoid-based } \\
\text { products }\end{array}$ & $\begin{array}{l}\text { Products aimed at medicinal use that contain cannabis or cannabinoids derived from } \\
\text { the cannabis plant; e.g., medicinal herbal cannabis (full plant extracts containing multiple } \\
\text { cannabinoids [unprocessed blossoms]), plant-extracted cannabinoids, or synthetic cannabinoids } \\
\text { that have not obtained the medicine agency approval. }\end{array}$ \\
\hline $\begin{array}{l}\text { Approved by } \\
\text { medicines agencies } \\
\text { cannabinoid-based } \\
\text { products }\end{array}$ & $\begin{array}{l}\text { Pharmaceutical-quality preparations containing purified cannabinoids, e.g., THC and CBD. These } \\
\text { include natural cannabinoid-based medicines (products that contain natural cannabinoids } \\
\text { [e.g., CBD or THC+CBD]) and synthetic cannabinoid-based medicines (products that contain } \\
\text { synthetic versions of cannabinoids [e.g., those that mimic the effects of } \mathrm{THC} \text { ) with regulatory } \\
\text { approval for use. }\end{array}$ \\
\hline \multicolumn{2}{|l|}{ Other } \\
\hline \multirow{4}{*}{$\begin{array}{l}\text { Non-medicinal-aimed } \\
\text { cannabinoid-based } \\
\text { products }\end{array}$} & $\begin{array}{l}\text { Materials derived from cannabis plants or synthetic that are not regulated for medicinal use. } \\
\text { These include different categories: }\end{array}$ \\
\hline & $\begin{array}{l}\text { 1. CBD-based products (e.g., food and beauty supplements) classified as food supplements, } \\
\text { THC content should be very low (different regulations across countries). }\end{array}$ \\
\hline & 2. Herbal (street) cannabis (for recreational use). \\
\hline & 3. Synthetic cannabinoids aimed for recreational use (e.g., spice/K-2) \\
\hline Industrial hemp & $\begin{array}{l}\text { Cannabis products specifically used for manufacturing and not consumption are typically } \\
\text { referred to as industrial hemp. }\end{array}$ \\
\hline
\end{tabular}

AEA: anandamide; CBD: cannabidiol; INN: international non-proprietary name; THC: tetrahydrocannabinol; 2-AG: 2-arachidonoylglycerol.

They recommended moving $\mathrm{THC}$ and its containing less than $0.2 \%$ THC be removed synthetic counterpart from Schedule 2 to from international control, given the absence of Schedule 1 as these are the compounds mostly responsible for the psychoactive properties of cannabis. Likewise, they also recommended that THC isomers should be included in Schedule 1 based on current knowledge. ${ }^{33}$ In contrast, the WHO recommended that CBD products relevant risk to public health.33

These proposals were voted on by the Commission of Narcotic Drugs (CND) in March 2019, however, the vote was postponed and the recommendations were delayed. ${ }^{33}$ Despite delays, 
these recommendations suggest a relaxation of regulations for cannabis-based products with demonstrating medicinal efficacy.

To date, more than 50 countries have in some way legalised access to cannabis-based products for medicinal and/or recreational use under different frames and regulations..$^{34,35}$ Table 2 details some relevant examples about the variability in laws of some countries in Europe and indicates that there is currently no harmonised European Union (EU) law regarding the use of cannabis products. ${ }^{9,35,36}$ Notably, those medicinal products with specific regulatory approval from the EMA and FDA are not included here but are discussed in Chapter 3 .

\section{Public Misconceptions: A Knowledge Gap}

One aspect of public opinion that should be addressed when considering the perception of cannabis is the general understanding of cannabis and its derived products.

Table 2: Regulation of recreational and medicinal use of cannabis and cannabis-based products remains varied in Europe.

\begin{tabular}{|c|c|c|}
\hline Country & Recreational use & Medicinal use \\
\hline France & $\begin{array}{l}\text { Illegal. Entails a fine of up to } 200 \text { EUR, } \\
\text { since } 2018 .\end{array}$ & $\begin{array}{l}\text { Some cannabis-based products } \\
\text { authorised from } 2013 .\end{array}$ \\
\hline Germany & $\begin{array}{l}\text { - Illegal, but occasionally tolerated. } \\
\text { - Under federal law, prosecution } \\
\text { is optional for possession of 'small } \\
\text { amounts'. } \\
\text { - Consumption considered legal self- } \\
\text { harm. }\end{array}$ & $\begin{array}{l}\text { Approved products through the } \\
\text { BfArM, German medicines agency. } \\
\text { Legal herbal compounds use since } \\
2017 \text { for patients with no therapeutic } \\
\text { alternatives. }\end{array}$ \\
\hline Italy & $\begin{array}{l}\text { - Decriminalised. } \\
\text { - Allowed for religious usage. } \\
\text { - Legal below } 0.6 \% \mathrm{THC} \text {. }\end{array}$ & $\begin{array}{l}\text { Approved products through the AIFA, } \\
\text { Italian medicines agency. Licensed } \\
\text { cultivation for medicinal and industrial } \\
\text { use tightly regulated. }\end{array}$ \\
\hline Spain & $\begin{array}{l}\text { - Use and possession in private } \\
\text { allowed. } \\
\text { - Public consumption can result in a } \\
\text { fine. } \\
\text { - Cultivation for personal use allowed } \\
\text { in private areas including cannabis } \\
\text { social clubs. }\end{array}$ & $\begin{array}{l}\text { Approved products through the } \\
\text { AEMPS medicines agency. }\end{array}$ \\
\hline Portugal & $\begin{array}{l}\text { Decriminalised up to } 25 \mathrm{~g} \text { of herb or } \\
5 \mathrm{~g} \text { of hashish. }\end{array}$ & $\begin{array}{l}\text { Approved products through the } \\
\text { Portuguese medicines agency. Legal } \\
\text { herbal compounds use. }\end{array}$ \\
\hline UK & $\begin{array}{l}\text { Illegal. Banned in } 1928 \text { and made a } \\
\text { Class B drug under the Misuse of } \\
\text { Drugs Act in } 1971 .\end{array}$ & $\begin{array}{l}\text { Approved products through the } \\
\text { MHRA, UK medicines agency. } \\
\text { Legal for cases of severe epilepsy, } \\
\text { vomiting, or nausea caused by } \\
\text { chemotherapy or MS when prescribed } \\
\text { by a registered specialist doctor. }\end{array}$ \\
\hline The Netherlands & $\begin{array}{l}\text { - Illegal but use and sale is tolerated in } \\
\text { licensed coffee shops. } \\
\text { - Possession of up to } 5 \mathrm{~g} \text { is } \\
\text { decriminalised. } \\
\text { - Cultivation of up to } 5 \text { plants is } \\
\text { unenforced for non-commercial use } \\
\text { (unless grown in a professional setup). }\end{array}$ & Legal herbal compounds use. \\
\hline Denmark & Illegal. & $\begin{array}{l}\text { Legal (a 4-year pilot programme } \\
\text { began in January 2018). }\end{array}$ \\
\hline
\end{tabular}




\begin{tabular}{|l|l|l|}
\hline Sweden & Illegal. & $\begin{array}{l}\text { Illegal. All cannabis-related activity is } \\
\text { illegal. }\end{array}$ \\
\hline Belgium & $\begin{array}{l}\text { Decriminalised up to } 3 \mathrm{~g} \text { or cultivation } \\
\text { of one plant since } 2003 .\end{array}$ & Cannabis-derived drugs are permitted. \\
\hline Georgia & $\begin{array}{l}\text { Legal for possession and consumption } \\
\text { but not for sale, per a July } 2018 \text { ruling } \\
\text { by the Constitutional Court of Georgia. }\end{array}$ & $\begin{array}{l}\text { Use is legal, but no system for the } \\
\text { dispensing of cannabis exists. }\end{array}$ \\
\hline Croatia & $\begin{array}{l}\text { Decriminalised. Possession of small } \\
\text { amounts is considered a misdemeanor } \\
\text { which leads to a fine. }\end{array}$ & $\begin{array}{l}\text { Medicinal cannabis is legal for patients } \\
\text { willnesses such as cancer, MS, or }\end{array}$ \\
\hline
\end{tabular}

AEMPS: The Spanish Agency of Medicines and Medical Devices (Agencia Española de Medicamentos y Productos Sanitarios); AIFA: Italian Medicines Agency; BfArM: The Federal Institute for Drugs and Medical Devices

(Bundesinstitut für Arzneimittel und Medizinprodukte); MHRA: Medicines and Healthcare products Regulatory

Agency; MS: multiple sclerosis; THC: tetrahydrocannabinol.

For example, the 2019 EU CBD Consumer Report stated that $25 \%$ of the survey respondents believed that consumption of the non-intoxicating cannabinoid CBD would get the user high, while a further $28 \%$ stated that they were unsure if it would. ${ }^{37}$ The report also noted that $21 \%$ of CBD users cited social media as their primary source of information of CBD, while 18\% identified friends and family as their information source. ${ }^{37}$ While the information they receive from these sources may not be inaccurate, it is important to be aware that many medicinal cannabis users are not receiving information from traditionally reliable resources and, in order to increase public understanding of cannabis, its derived products, and its potential therapeutic benefits, these resources must be available and easily accessible to them.

\section{"Endocannabinoid systemic expectations} are probably more important than other treatments. This could explain why some people do not respond to recreational cannabinoids, because they perceive them to be addictive drugs when they could respond to cannabinoid formulations, which are, instead, perceived as medical products." Diego Centonze

There are projects within Europe that aim to increase understanding and awareness of medicinal cannabis. Project Twenty21, launched in November 2019, aims to create a body of evidence from 20,000 patients to demonstrate the effectiveness and tolerability of medicinal use of cannabis, with the ultimate aim to convince European policy-makers that medicinal use of cannabis should be made widely available to the public. ${ }^{38}$ The project uses real-world data to document the effectiveness, safety, and quality of life for those prescribed medicinal cannabis for certain conditions, including chronic pain, epilepsy, and multiple sclerosis (MS). ${ }^{39}$ These kinds of initiatives will certainly increase the knowledge about the medical possibilities of cannabinoids, but the absence of proper control groups together with the variability of tracked compounds and diseases will lead to gathering evidence of limited scientific quality.

A lack of knowledge surrounding cannabis, cannabis-derived products, and cannabinoidbased medicines is not just limited to the general public; it appears that healthcare professionals themselves may be just as untrusting about the use of cannabis for medicinal purposes. For example, in the UK, after the rescheduling of cannabis from a Class A drug in November 2018 , 18 National Health Service (NHS) prescriptions had been issued prescribing cannabis for medicinal use 6 months later, ${ }^{40}$ suggesting that there is little support from healthcare professionals for their patients to use unlicensed medicinal cannabis as a potential treatment 
option. The approach of healthcare professionals is relevant because a broad survey reflected that $76 \%$ of people who did not use cannabinoids stated that doctor recommendations would influence their decision in the future, ${ }^{37}$ while, of those who bought these products, 61\% stated that doctors' recommendations were an important factor that influenced the products they purchased.

"I would say the medical doctors in the last 5-8 years have a knowledge of the endocannabinoid system but that is a minority of the doctors today. So, doctors must have a knowledge of the endocannabinoid system. First, to understand this enormous target we have in our body, with an enormous potential in terms of developing medicine."

\section{Rafael Maldonado}

\section{CHAPTER 3: THE GROWING ROLE OF CANNABINOID-BASED PRODUCTS IN MEDICINE}

\section{The Endocannabinoid System}

In humans, the endocannabinoid system is a complex cell-signalling system known to modulate a number of physiological process pathways including sleep, appetite, mood, memory, muscle tone, peripheral sensitivity, reproduction, and fertility. ${ }^{28}$ The system is composed of three core components: cannabinoid receptors (among them, $\mathrm{CB}_{1}$ and $\mathrm{CB}_{2}$ as the two most important and best studied), the endogenous cannabinoids, also called endocannabinoids (AEA, 2-AG, and others), which bind to these receptors, and the enzymes responsible for their synthesis and breakdown, e.g., fatty acid amide hydrolase and monoacylglycerol lipase. ${ }^{41} \mathrm{CB}_{1}$ and $\mathrm{CB}_{2}$ receptors are members of the superfamily of $\mathrm{G}$-protein coupled receptors (GPCRs). ${ }^{42} \mathrm{CB}_{1}$ receptors are found predominantly in the CNS where they mainly mediate inhibition of both excitatory and inhibitory neurotransmitter release, ${ }^{41}$ and they are one of the most abundant GPCRs in the brain. Their location means that their activation impacts processes involved in cognition, memory, and analgaesia. ${ }^{42}$ In contrast, $\mathrm{CB}_{2}$ receptors, although being present in both the CNS and in neurons, are located predominantly in immune cells within the peripheral system and, when activated, play a role in modulating migration of immune cells and cytokine release. ${ }^{42}$ Activation of $C B$ receptors modulate the release of a variety of neurotransmitters including acetylcholine, GABA, dopamine, glutamate, and serotonin. Therefore, endocannabinoids within the body help prevent the excessive release of these neurotransmitters. ${ }^{43}$

One of the most important features of endocannabinoids that differentiates them from classic neurotransmitters is that they are synthesised upon demand, normally via activation of GPCRs, as opposed to being synthesised and stored in vesicles for future release. The first discovered and the most well-characterised endocannabinoids are AEA and 2-AG. ${ }^{44}$ AEA is colloquially known as the 'bliss molecule' due to the role that it plays in mood, appetite, and sleep, and has been identified as resembling THC. ${ }^{45}$ This has made anandamide a key point of research as a way to help understand how cannabis may be beneficial for use in humans.

Similarly to public interest, the two phytocannabinoids, which interact with the endocannabinoid system, that have received the most attention from a scientific research perspective are THC and CBD. ${ }^{7}$ THC has several effects, including psychoactive positive and negative properties, which can deliver the sensations that users associate with recreational cannabis use if doses are raised. ${ }^{7}$ In contrast, CBD does not produce psychoactive effects and is not intoxicating, even at high concentrations. ${ }^{7}$ CBD is thought to modulate other receptorindependent pathways, e.g., by delaying reuptake of endogenous neurotransmitters. Over 65 different targets of CBD have been identified within the human body, ${ }^{46}$ many deserving research in humans, and the vast possible effects and interactions across the body systems have still to be fully elucidated.

As already mentioned, the endocannabinoid system plays a vital role in many of the key systems in the human body, including stress regulation. Despite its importance, the system is extremely understudied. ${ }^{47} \mathrm{~A}$ deeper understanding of the endocannabinoid system, and how phytocannabinoids and their synthetic counterparts can interact with this system, could be the key to finding effective new 
therapeutic treatments in the future. Moreover, having a better grasp of the endocannabinoid system could provide solutions to the currently unanswered questions in medicine. ${ }^{46}$

\section{"The endocannabinoid system modulates a} lot of responses: pain, movement, emotional response, food intake; so, imagine the possibilities." Rafael Maldonado

\section{"All basic biological functions are regulated by endocannabinoid system. The reason why this is the case is probably to be related to the ancient role of these lipid systems in the biology." Diego Centonze}

\section{Why Do Some Cannabinoid-Based Products Have Therapeutic Benefits?}

There are a number of therapeutic areas in which the potential of cannabinoid-based products has been explored. These include spasticity in MS, cancer-associated pain, neuropathic pain, HIV/AIDS wasting, rheumatoid arthritis, and sleep disorders. ${ }^{7}$ Understanding exactly how different cannabinoid-based products may elicit a therapeutic effect has received a growing amount of attention over the years, and scientists have focused their research efforts on THC and CBD alone or in combination. Importantly, these two compounds have shown clearly different properties on the human endocannabinoid system. These differences may help explain the possible therapeutic benefits, dependant on dosages and combinations. ${ }^{7}$

Endocannabinoids are lipid-soluble molecules and are broken down relatively quickly by metabolic enzymes. This means they predominantly serve as modulators of only smallscale localised neurotransmitter release. ${ }^{43}$ In contrast, THC takes much longer to be broken down by human metabolism and thus is able to activate all CB receptors. ${ }^{43} \mathrm{THC}$ acts as a partial agonist of both $\mathrm{CB}_{1}$ and $\mathrm{CB}_{2}$ receptors; the effects of $\mathrm{THC}$ on $\mathrm{CB}_{1}$ receptors in the CNS is responsible for its observed effects on mood, cognition, and behaviour. ${ }^{48}$ Conversely, CBD has a low binding affinity for both $C B_{1}$ and $C_{2}$ receptors but is able to antagonise at different doses the effects of $\mathrm{THC}$ on $\mathrm{CB}_{1}$ receptors ${ }^{18}$ through negative allosteric modulation. CBD inhibits the degradation of endogenous cannabinoid AEA, and in doing so, it has been postulated that it may prevent THC from interacting with the $C B$ receptors. ${ }^{43}$ The physiological effects of $C B D$ are more poorly understood by comparison with $\mathrm{THC}$. It has been reported that CBD alone has little to no effect on normal physiological processes. Instead, it has been postulated that only when a stimulus (like pain or shock), or another cannabinoid (like THC) has upset the normal equilibrium, does CBD have an impact. ${ }^{43}$ Considering this, $\mathrm{CBD}$, within its interactions with different pathways receptors, may offset the unwanted psychoactive effects of THC, as studies in humans support that CBD can reduce THC psychoactivity perception, ${ }^{49}$ and, as such, may contribute to safety, as well as therapeutic benefit. For medicinal preparations of cannabinoid-based products, this combinatorial approach would allow efficacy as mediated by THC while maintaining safety through the antagonistic effects of CBD and serves as an important differentiator to those unregulated products, whereby a mixture of THC and CBD is not controlled in this way. Each fixed-dose combination of active principles (such as THC plus CBD) has to demonstrate addition or potentiation of effects and appropriate tolerability and safety when given together to be declared useful. This necessity makes the study of mixtures with more than two components difficult.

\section{Cannabinoid-Based Medicines: A Growing Evidence Base}

As more countries legalise the medicinal use of cannabis-based products, scientific evaluation and assessment of their efficacy for therapeutic purposes is paramount. ${ }^{50}$ There is a clear need to assess efficacy and safety of already legalised cannabinoid-based products in well-designed clinical trials to ensure the same rigorous clinical evaluation as any other therapeutic agent. However, until results become available, transitional regulations are needed to allow legal access for patients to use cannabis-based products. Compassionate use programmes and the named patients' medication access programmes that allow product access can be established for compounds with initial effectiveness data and apparent non-problematic tolerability. Opponents to the Schedule 1 classification of cannabis and its related products 
have suggested that the restrictive laws have posed a significant barrier to large numbers of clinical trials investigating their efficacy and safety for medicinal purposes. ${ }^{7}$ Despite this, a systematic review and other meta-analyses of available clinical trial data (between 19752015) assessing the efficacy of cannabinoidbased medicines versus placebo, standard of care, or no treatment, across multiple disease conditions indicated a growing body of clinical evidence to support the use of these products for medicinal purposes. ${ }^{18,51}$ The systematic review evaluated data from 79 trials of different cannabinoid products across 6,462 participants and concluded that certain cannabinoidbased treatments demonstrated moderate improvement in symptoms, while evidence was limited (as improvements did not always reach statistical significance, study designs could be improved and samples were not large).18,50 Other recent publications ${ }^{52}$ came to similar conclusions, suggesting conclusive or substantial evidence showed that certain cannabinoid products can be effective for the treatment of pain in adults, chemotherapy-induced nausea and vomiting, and spasticity associated with MS. They found moderate evidence for secondary sleep disturbances. The evidence supporting improvement in appetite, Tourette syndrome, anxiety, post-traumatic stress disorder, cancer, irritable bowel syndrome, epilepsy, and a variety of neurodegenerative disorders was described as limited, insufficient, or absent.

In particular, clinical trials assessing the benefits of cannabinoid-based medicines for symptom improvement in patients with nausea and vomiting due to chemotherapy, orexigenic effects in patients with HIV/AIDS, MS spasticity, chronic neuropathic or cancer pain, anxiety disorder, sleep disorder, psychosis, Tourette syndrome, and paraplegia have all reported improvements with cannabinoid-based medicines versus placebo. ${ }^{7}$ While limitations are expected in similar analyses to extract generalised conclusions with respect to methodology, product compositions, dosing, and administration route variation between studies, this evidence seems promising for cannabinoid-based medicines..$^{18}$ Interestingly, studies with pure THC or its THC-mimicking synthetic counterparts, such as nabilone, were not found to be effective in trials to assess efficacy in conditions including Alzheimer's disease, Parkinson's disease, and $\mathrm{MS}^{24}$ Combinations of $\mathrm{THC}$ and $\mathrm{CBD}$, and $\mathrm{CBD}$ alone, however, were shown to be more promising. ${ }^{24}$

Anecdotal reports of the efficacy of herbal cannabis preparations, while available, have proven to be variable within the non-standardised preparations that have been tested. ${ }^{24}$ Increased clinical evidence for, and validation of medicinal fixed-ratio cannabinoid-based treatments in this way, has seen a select number of treatments now approved by medicines agencies for the treatment of certain indications. Importantly, this marks a key point of differentiation from other cannabinoid-based preparations that have not gathered as strong an evidence base. Table 3A provides details of those therapy areas that have to date received authorisation for treatment with medicinal cannabinoids. ${ }^{18,53}$

\section{Continued Research in Cannabinoid- Based Medicines}

As the understanding of the endocannabinoid system and its components grow, the development of agents that are able to modulate it can be expected to expand in parallel. While 'raw' herbal preparations of cannabis contain a complex mixture of cannabinoids, all with distinct properties, careful manipulation of specific components in pharmaceutical-grade preparations may serve as highly targeted and efficacious means of treating different conditions. $^{18}$ Other cannabinoids may prove to be useful treatment options in the future. Cannabigerol, alongside CBD, for example, are known to be epigenetic regulators of gene expression and these may prove beneficial when considering personalised medicine. Further understanding of how specific targeting of the $C B$ receptors can support alleviation of symptoms of different conditions is also of great research interest. ${ }^{18}$ Nevertheless, full elucidation of the safety profile of each individual medicinal cannabinoid product is also of crucial importance such that inappropriate abuse of these products can be avoided. ${ }^{18}$ There are a number of clinical trials that are ongoing or due to be initiated to further explore the role of cannabinoid products for the management of multiple conditions. Examples include, for instance, cannabinoids for behavioural problems in children with autistic disorder (20:1 ratio of $\mathrm{CBD}: \mathrm{THC})^{55}$ and cannabinoids for the 
Table 3A: Indications that have received regulatory authorisation for treatment with medicinal cannabinoids to date.

\begin{tabular}{|l|l|}
\hline Cannabinoid/active principle & Approved indications* \\
\hline Nabilone THC synthetic/nabilone THC synthetic analogue & $\begin{array}{l}\bullet \text { Treatment of chemotherapy-induced nausea and } \\
\text { vomiting in patients who have failed to respond adequately } \\
\text { to conventional antiemetic treatments. } \\
\text { - Appetite stimulant (HIV/AIDS). }\end{array}$ \\
\hline THC/CBD 1:1 ratio & $\begin{array}{l}\text { - Treatment of spasticity due to MS in those patients who } \\
\text { have not responded adequately to other anti-spasticity } \\
\text { medication. This treatment is intended as an add-on to } \\
\text { additional anti-spasticity medication. }\end{array}$ \\
\hline CBD & $\begin{array}{l}\text { - Childhood epilepsy (adjunctive therapy of seizures } \\
\text { associated with LGS or Dravet syndrome, in conjunction } \\
\text { with clobazam, for patients } 2 \text { years of age and older). }\end{array}$ \\
\hline
\end{tabular}

Note that marketing authorisation details and indications may vary between countries.

CBD: cannabidiol; LGS: Lennox-Gastaut syndrome; MS: multiple sclerosis; THC: tetrahydrocannabinol.

Adapted from Maccarrone et al. (2017) and Krcevski-Skvarc et al. (2017).18,54

treatment of hyperalgaesia in patients with deep endometriosis (1:1 ratio of CBD:THC). ${ }^{56}$ Moreover, exploring alternate delivery methods beyond the common current options (tablet, capsules, liquid, or oromucosal spray) may be beneficial in the treatment of conditions that have previously not been considered.

An ongoing clinical trial is investigating whether a topical cannabinoid patch can reduce pain in patients with osteoarthritis in the knee. ${ }^{57}$ Non-oral delivery methods such as this may overcome reservations that can accompany oral administration. Table 3B details indications where cannabinoids are being explored for their present or potential uses as treatments in the future. . $^{18,54-56}$

\section{CHAPTER 4: DIFFERENTIATING APPROVED CANNABINOID- BASED MEDICINES FROM OTHER CANNABINOID-BASED PRODUCTS}

\section{Cannabinoid-Based Medicinal Drug Products}

California's authorisation of botanical cannabis in 1996 initiated a global change in practices and consideration of how cannabis-based products are regulated. Since 1996, many other regions or countries have followed suit, authorising the use of cannabis for medicinal-aimed purposes. ${ }^{17}$ Importantly, however, this does not necessarily mean approval from a regulatory agency (e.g., EMA and FDA); instead, legislation may be in place allowing the use of cannabis or cannabisbased products in certain circumstances (for specific, restricted medicinal purposes). This change represents a huge shift in regulatory processes, as a product may be authorised as a result of legislation rather than the formal drug development and regulatory approval process. ${ }^{17}$

As a result of these changes in legislation, current laws in a number of European countries do not necessarily prohibit the use of cannabis, approved or not, for the management of some defined conditions (Table 1). ${ }^{7}$ There are, however, important variations when we consider the types of medicinal cannabis-based products that are available. Considering herbal cannabis used in its direct form for medicinal purposes, dried female flowers from the cannabis plant are legalised for medicinal use in some countries in Europe. Indeed, different varieties of cannabis plants may be cultivated in such a way as to generate many different levels of THC, CBD, or other compounds. While these products meet the standards of good agricultural practice and are ISO 9001 certified, they are yet to be clinically tested for specific disease indications. ${ }^{17}$ 
Table 3B: Indications where cannabinoids are being explored for their potential as treatments in the future.

\begin{tabular}{|c|c|}
\hline Cannabinoid & Potential indications \\
\hline THC & $\begin{array}{l}\text { - MS spasticity. } \\
\text { - Neuropathic pain in MS. } \\
\text { - Cancer pain unresponsive to opioids. } \\
\text { - Post-traumatic stress disorder. } \\
\text { - Mild to severe dementia. } \\
\text { - Marijuana abuse. } \\
\text { - Fibromyalgia. } \\
\text { - Other pain conditions (e.g., post-herpetic neuralgia, post- } \\
\text { operative pain). }\end{array}$ \\
\hline THC/CBD & $\begin{array}{l}\text { - Paraplegia, amyotrophic lateral sclerosis. } \\
\text { - Neuropathic pain in MS. } \\
\text { - Cancer pain unresponsive to opioids. } \\
\text { - Other pain conditions (e.g., post-herpetic neuralgia, post- } \\
\text { operative pain). } \\
\text { - Autistic disorder. } \\
\text { - Deep endometriosis. } \\
\text { - Tourette syndrome. }\end{array}$ \\
\hline CBD & $\begin{array}{l}\text { - Mild to moderate musculoskeletal pain. } \\
\text { - Chronic pain. } \\
\text { - Anxiety. } \\
\text { - Post-traumatic stress disorder. } \\
\text { - Psychosis. }\end{array}$ \\
\hline THC, THC/CBD, and others & $\begin{array}{l}\text { - MS, bladder dysfunction due to MS, dyskinesias of } \\
\text { Huntington's disease, levodopa-induced dyskinesias } \\
\text { in Parkinson's disease, cervical dystonia, epilepsy, and } \\
\text { Alzheimer's disease. } \\
\text { - Joint pain. }\end{array}$ \\
\hline
\end{tabular}

Most relevant areas depicted.

CBD: cannabidiol; MS: multiple sclerosis; THC: tetrahydrocannabinol.

Adapted from Maccarrone et al. (2017) and Clinicaltrials.gov. (18,54-56 $^{-12}$

In addition, most current European laws support cannabis-based products of this type to be administered via a vapouriser or oral route. To date, no European country recommends smoking for any purpose.,9 The reason for this, beyond the inherent damage to respiratory tract tissues following smoking cannabis, even tobacco-free, is likely based on the ability to regulate dose in a consistent manner.

Smoking cannabis impairs tight regulation of dose, as different depth and frequency of inhalations generates a high variability of intake and, importantly, is challenging to replicate consistently across multiple doses. ${ }^{9}$ Oral route intake of cannabis extracts limits these problems, but proper absorption, distribution, metabolism, and elimination studies have to be carried out for each product, followed by extensive clinical testing, to demonstrate the possible medicinal potential.

\section{Pharmaceutical Quality Preparations with Regulatory Approval for Medicinal Use}

There are also medicinal cannabis-based products available on the market that have been developed via the established drug development process. Despite being derived from 'raw' 
cannabis or synthetic version of the cannabinoids, they are developed to demonstrate proven efficacy, safety, and tolerability, and formulated to current medicinal and pharmaceutical standards just like any other therapeutic agent. ${ }^{17}$ Identification of the specific cannabinoids, doses, and administration routes that may be best suited for a medicinal purpose serves to allow a targeted (and potentially safer) approach to drug development, whereby a specific mechanism of action can be elicited (e.g., full agonism of $\mathrm{CB}_{1}$ receptors outside of the CNS). ${ }^{17}$ This is the rationale behind medicinal cannabinoidbased products that are based on a specific formulation of cannabinoids. Moreover, careful combination of specific compounds derived from the cannabis plant and/or synthetic variations may allow what is also referred to as the 'entourage effect', meaning that a combinational approach may serve to enhance therapeutic effect (e.g., certain cannabinoids may be able to act synergistically). While further work is needed to understand the exact impact that the entourage effect could have, there appears to be benefits of the careful combination of specific endocannabinoid components for therapeutic effect. In any case, each combination, dose regimen, and route should be properly tested for their effects and risk-benefit balance. Again, this provides a point of differentiation for approved medicinal cannabinoid-based products and both the single cannabinoids and herbal cannabis, and extracts made from cannabis.

Manufacturing of medicinal cannabinoid products is another area that requires consideration; in particular, the need for regulated botanical production, from growing to processing. Demonstrating consistency across and within batches is crucial for the authorisation of these products, ${ }^{17}$ particularly those that promise specific fixed, formulated ratios of cannabinoid components. Fixed genetic composition, reproducible chemical profiles, breeding programmes, genetic stability studies, cloning, in vitro tissue recovery, and good manufacturing practices are all crucial. ${ }^{39}$ Indeed, bioengineering of cannabinoids is being considered as a potential replacement to the traditional cannabis plants, as the desired molecules could be produced more efficiently and reliably. ${ }^{58}$
Some products with regulatory approval for medicinal use are synthetically produced to mimic the effects of naturally derived cannabinoids (e.g., THC, synthetic THC, or synthetic THC analogue [nabilone]). These are pharmaceutical-grade products that can be chemically identical to the cannabinoid compounds that are found within the cannabis plant (e.g., synthetic THC) or analogous to them, binding to the $\mathrm{CB}$ receptors with different potencies. ${ }^{17}$ As with those products derived directly from the cannabis plant, these synthetic preparations have also been assessed and validated in a number of clinical trials. ${ }^{59-61}$ Approved indications for these preparations include the treatment of chemotherapy-induced nausea and vomiting and weight-loss treatment in patients with AIDS.,17 Synthetic cannabinoidbased products have different approval statuses across the world (Table 3A). Currently, countries including the USA, the Netherlands, Austria, Germany, and Croatia allow the use of synthetic cannabis-based medicinal products, predominantly those that mimic the effects of THC. However, in the UK, although some are licensed, others are not, but may be prescribed on a named patient basis. ${ }^{7}$

There may be a misconception that synthetic forms of medicinal cannabis-based products are more harmful than those derived directly from the cannabis plant; specifically, concern over the recreational and abused forms of synthetic THC currently on the market are likely driving these fears. ${ }^{62}$ Synthetic formulations of cannabinoid preparations as authorised for medicinal use have been formulated with the exact chemical composition and structure. Any differences in effect would therefore be due to the presence of impurities or missteps in the synthesis of the cannabinoid. ${ }^{7}$ Synthetic cannabinoids can be either research tools, potential medicines, or illicit abuse substances, like spice/K-2. These latter drug effects are different and more toxic, not only because of impurities or missteps, but intentional inclusion of analogues of cannabinoids with more potent cannabinoid pharmacology and other target effects.

\section{Non-medicinal Cannabis-Based Products: Cannabidiol and Further}

Since the removal of hemp from the list of controlled substances by the FDA in December 
2018, ${ }^{29}$ CBD has become a popular ingredient in a number of consumer products, as listed earlier, including skin lotions, bath salts, flavoured gummies, face masks, beverages, chocolate bars, and tinctures. CBD is also being made available in pet products. ${ }^{63}$ There is a growing availability of products containing CBD in health food shops, online, and elsewhere claiming health benefits, despite not being regulated as medicines. This 'Green Rush' for CBD began in 2015 and reflects an increasing trend for the development of products containing CBD. ${ }^{64}$

In the EU, cultivation of varieties of cannabis plants for the purpose of CBD-based products is authorised provided they are registered as part of the EU common catalogue of varieties of agricultural plant species and the THC content of the plant's dried flowers must be no more than $0.2 \%{ }^{65,66}$ This threshold for possible THC concentration varies across the world; in Canada, CBD products can contain up to $0.3 \%$, while in Switzerland, CBD products may contain up to $1.0 \% \mathrm{THC}^{64}$

In the Netherlands, cultivation of hemp plants is authorised, but only for the production of hemp fibres or seeds; cultivation of these plants for their CBD is a violation of narcotic law. ${ }^{64}$ Varieties of plant cultivated to increase CBD yields remain under regulatory assessment and, as such, cannot yet be freely cultivated. ${ }^{64}$ The declared content of CBD in some products, however, may be variable and may be reported inaccurately, or not accurately measured. In these products, levels of THC may also exceed the legal limit.7 In a study carried out in the Netherlands, 26/46 samples of CBD oil tested were found to contain more than the accepted $1 \%$ THC, with one sample containing over 57\%. Additionally, in 18 of the samples, CBD was barely present at all, with the predominant ingredient being virtually only THC. ${ }^{64}$ Products of this nature are, therefore, seemingly not always produced as per regulations and quality controlled as those for approved medicinal use, meaning caution must be exercised. Unregulated products of this nature may also be contaminated with potentially harmful products including those added to improve yield, weight, or potency (pesticides, synthetic cannabinoids, metal particles, bacteria, etc.). ${ }^{64}$ Chemicals used to purify CBD for cosmeticbased products, for instance, may also be left behind during the purification process and may result in the presence of toxic solvents in the final CBD preparation. ${ }^{64}$

Beyond the reviewed products, other nonmedicinal products include 'raw' forms of herbal cannabis that may be smoked or eaten for recreational use and non-medicinal synthetic cannabinoids. Evidence suggests that increased consumption of these products occurs among young adults and adolescents. In particular, home-grown 'indoor cannabis' has been shown to be potentially 10- to 15-times more potent than the classical 'herb'.18 Non-medicinal synthetic cannabinoids, also referred to as 'legal highs', new psychoactive substances, or 'spice', must be differentiated from all other above discussed cannabinoids because they can be harmful to health or even fatal.

\section{CHAPTER 5: ADVERSE EVENTS, INCLUDING PSYCHOSIS RISK, WITH CANNABIS-BASED PRODUCTS}

Increasing levels of THC as opposed to the traditional herbal cannabis plants have been reported in the composition of latest street herbal batches and numerous unregulated nonmedicinal cannabis-based products. In the 1970s, the average THC content in cannabis plants tested in parts of Europe was estimated to be less than $3 \%$. Current varieties are now reported to contain an average of nearly $20 \%$, and, in some, may be as high as 40\%. ${ }^{67}$ This increase in THC content is most likely due to high-THC-content plants commonly being cultivated in favour of low-THC-content plants. ${ }^{68}$ Research has long established an association between cannabis use and the onset of psychotic disorders. ${ }^{66}$ In fact, a recent study reported that people who regularly use high-strength cannabis may be up to 5-times more likely to experience psychotic symptoms, such as being temporarily disconnected from reality, experiencing visual or auditory hallucinations, or suffering from paranoia. ${ }^{69,70}$ Early age of use initiation (i.e., during teenage years) and daily amount of THC is also highly correlated with these risks. 


\section{How Does Tetrahydrocannabinol Elicit Unwanted Psychoactive and Neurological Effects?}

The negative psychoactive properties of cannabis are attributed mainly to THC, which has a similar chemical structure to the naturally occurring endocannabinoid AEA. ${ }^{11}$ Cannabinoids modulate brain areas that influence pleasure, memory, concentration, cognition, and movement and elicit their function via interaction with central $\mathrm{CB}_{1}$ receptors. ${ }^{70,71}$ Because of its structural similarity, THC also acts as a cannabinoid receptor agonist; 70 consequently, it may disturb the natural signalling, with detrimental effects on different brain functions such as memory formation and co-ordination. Use of these cannabinoid products may, therefore, carry the risk of impaired cognition and focus, and an inability to operate vehicles and heavy machinery. ${ }^{70}$ This adds to the known risk of triggering psychotic disorders, as well as other non-psychiatric adverse effects related to continuous cannabis use, such as testicular cancer, sexual dysfunction and infertility, cannabis hyperemesis syndrome, increased cardiovascular events, cannabis use disorder, and cannabis withdrawal syndrome. Again, each cannabinoidbased product must be carefully studied to characterise its own efficacy, tolerability, and safety profile to optimise its risk-benefit ratio.

Beyond the efficacy results, research of each cannabinoid-based product medicinal use should raise specific data on its short- and long-term safety and tolerability profile based on a broad enough sample of subjects within the aimed condition frame.

Data to be proactively collected should include information about the incidence and severity of the known cannabinoid-related possible adverse events, which have been described mainly when cannabinoids have been used recreationally, looking for the psychoactive effects produced by high THC levels such as psychiatric conditions triggering psychotic episodes, long-term impact on cognition, abuse and addiction, cardiovascular disorders, and others.

Detailed collection of tolerability and safety data on especially susceptible subject groups should be foreseen if they are to use the product, such as elderly people, children and teenagers (with attention to the possible neurological development impact), pregnant people, and others.

Furthermore, the route of administration of cannabinoid-based products may also prove to have an impact not only on their efficacy but also on the tolerability and safety profile associated with them. In general, inhalation of cannabinoids and $\mathrm{THC}$ results in faster onset of action, higher THC concentrations in the blood and brain, but shorter duration of action compared to oral intake. For instance, smoking cannabis has shown in different studies association with progressive loss of cognitive function and increased incidence of certain psychiatric conditions, especially when happening in younger subjects, and has been correlated to its high cannabinoid blood levels. ${ }^{71}$ Long-term use study outcomes support the view that sustained misuse of cannabis, irrespective of its route of administration, can provoke brain damage; brain imaging studies have reported morphological changes in specific brain regions. While there is important variability within study results, likely due to methods and subjects' variations, the most affected areas are consistently those rich in $\mathrm{CB}_{\text {. }}$ receptors, such as the hippocampus, amygdala, orbitofrontal cortex, insula, and striatum. ${ }^{71}$

The antagonistic effects of CBD may help to alleviate the psychoactive properties of THC. In doing so, medicinal preparations of cannabinoids that balance the ratio of THC and CBD may be able to negate some potentially harmful side effects. $^{49}$ A meta-analysis of adverse events associated with THC and CBD preparations reported that side effects were mostly mildto-moderate and most commonly included dizziness or vertigo. ${ }^{18,73}$ While there is evidence to suggest that certain medicinally formulated cannabinoid products can have adequate safety profiles when administered at the recommended dose and frequency, this differentiation of medicinal products from those without an approved label or for recreational use (without this regulation) is important ${ }^{48}$ as randomised clinical trials establish the dimension of each product risk-benefit profile, allowing appropriate informed decisions for managing patients. ${ }^{48}$ Some have raised concerns that the acceptance of medicinal cannabis-based products may have a detrimental impact on the way recreational users perceive the risks of their 
own unregulated cannabis use. ${ }^{48}$ There is a need to clearly distinguish between the medicinal use of cannabinoid-derived products as a pharmaceutical drug delivered in a regulated and controlled dose, and the unproven riskbenefit balances associated with non-approved products, including recreational misuse and abuse possibility quantification. As with any therapeutic drug, there are serious side effects that may occur and potentially an increase in frequency when not appropriately prescribed or administered. ${ }^{48}$

\section{CHAPTER 6: CONCLUSION}

It is clear that beyond widespread use of cannabis and its derivatives throughout history, scientific research efforts have made considerable advances in our understanding of the way in which cannabinoid-based products can elicit their effects, their relative therapeutic potential, and potential risks of different products. Despite these advances, a crowded and somewhat unstructured availability in many countries has meant that there remains a need to clearly differentiate between the different cannabinoid-based products and their proven uses and effects. Most importantly, there is a need to distinguish those products authorised for medicinally aimed uses (from a purely legislative perspective), those authorised for medicinal use after approval by regulatory authorities such as the EMA and FDA, and those unregulated products used mainly recreationally or as food supplements. There is also a need to provide further clarity on the ways in which each of these products may be formulated and regulated, and how this may contribute to their relative riskbenefit profile.

Variations in law enforcement, cultural perceptions, and clinical evidence robustness have likely influenced this differentiation challenge and the way in which these products are perceived and understood by patients, healthcare professionals, and society in general. Moreover, the sheer variety of cannabis plant species, alongside the range of cannabinoid compounds within these plants and their combination possibilities, further emphasises a complexity to these products that remains potentially misunderstood or misinterpreted. With this in mind, it is important to identify points of differentiation for these products so that those with the potential for legitimate medicinal purposes can be further investigated and explored for their therapeutic benefits in patients.

Encouragingly, there is a growing body of clinical evidence to support the medicinal use of specific cannabinoid-based products for the treatment of certain conditions including, but not limited to, spasticity due to MS, chronic neuropathic pain, rare forms of childhood epilepsy, and end-of-life care. For some of these indications, regulatory approvals have already been obtained, while for others further research is ongoing. As we continue to understand the role of the different cannabinoids in medicine and the scope of the role that these products may play in the future, it is important that we are able to identify and define important differences between these products.

\section{References}

1. Appendino G. Domesticating cannabis. 2019. Available at: https:// themedicinemaker.com/discoverydevelopment/domesticatingcannabis. Last accessed: December 2020.

2. Desjardins J. The 6,000-year history of medical cannabis. 2018. Available at: https://www.visualcapitalist.com/ history-medical-cannabis-shown-onegiant-map/. Last accessed: December 2020.

3. Starr M. Earliest evidence of people 'smoking' weed found in 2,500-year- old Chinese pots. 2019. Available at: https://www.sciencealert.com/ ancient-pots-from-china-revealhumans-smoking-cannabis-2-500years-ago. Last accessed: December 2020.

4. Narconon. Cannabis 3,000 BC-1,500 AD. Available at: https://www. narconon.org/drug-information/ cannabis-3000bc-1500ad.html. Last accessed: December 2020.

5. History.com. Marijuana. 2019. Available at: https://www.history.com/ topics/crime/history-of-marijuana.
Last accessed: December 2020.

6. Britannica ProCon.org. Historical timeline. History of marijuana as medicine - 2900 BC to present. 2019. Available at: https:// medicalmarijuana.procon.org/ historical-timeline/. Last accessed: December 2020.

7. Freeman TP et al. Medicinal use of cannabis based products and cannabinoids. BMJ. 2019; 365:1141.

8. Sensiseeds.com. Cannabis in Germany - laws, use and history. 2020. Available at: https://sensiseeds. 
com/en/blog/countries/cannabisin-germany-laws-use-history/. Last accessed: December 2020

9. European Monitoring Centre for Drugs and Drug Addiction. Medical use of cannabis and cannabinoids. Questions and answers for policymaking. 2018. Available at: https://www. emcdda.europa.eu/system/files/ publications/10171/20185584 TD0618186ENN PDF.pdf. Last accessed: December 2020

10. Analytical Cannabis. US Google searches for CBD hit 6.4 million and continue to rise. 2019. Available at: https://www.analyticalcannabis.com/ articles/us-google-searches-forcbd-hit-64-million-and-continue-torise-312031. Last accessed: December 2020.

11. Leas EC et al. Trends in Internet Searches for cannabidiol (CBD) in the United States. JAMA Netw Open. 2019; 2(10): e1913853.

12. DW.com. Roth C. Global marijuana use rose by $60 \%$ over the past decade. 2019. Available at: https:// www.dw.com/en/global-marijuanause-rose-by-60-percent-over-thepast-decade/a-49358921. Last accessed: December 2020.

13. Science.howstuffworks.com. Bonsor $\mathrm{K}$ and Gerbis N. How marijuana works. Available at: https://science. howstuffworks.com/marijuana1.htm Last accessed: December 2020.

14. Eaze.com. Shiravi S. What is Indica? The ancient mountain strain is secretive and misunderstood. 2018. Available at: https://www.eaze.com/ article/what-is-indica-decoding-thedark-secrets-of-an-ancient-mountainstrain. Last accessed: December 2020

15. Atakan Z. Cannabis, a complex plant: different compounds and different effects on individuals. Therapeutic Advances in Psychopharmacology. 2012;2(6):241-54

16. Compass. Indica cannabis' history and origins. 2019. Available at: https:// www.compassclinics.com.au/blogs/ indica-cannabis-history-and-origins. Last accessed: December 2020.

17. Bonn-Miller MO et al. Cannabis and cannabinoid drug development: evaluating botanical versus single molecule approaches. Int Rev Psychiatry. 2018; 30(3):277-84

18. Maccarrone $\mathrm{M}$ et al. Cannabinoids therapeutic use: what is our current understanding following the introduction of THC, THC:CBD oromucosal spray and others? Expert Rev Clin Pharmacol. 2017;10(4):443 55.

19. Thestreet.com. Fiorillo S. 7 cannabis products on the rise. 2019. Available at: https://www.thestreet.com/ lifestyle/5-cannabis-productson-rise-14578907. Last accessed:
20. Shape.com. Astorino D. What's the difference between CBD, THC, cannabis, marijuana, and hemp? 2018. Available at: https://www.shape.com/ lifestyle/mind-and-body/differencebetween-cbd-thc-marijuana-hempcannabis. Last accessed: December 2020.

21. Prohibition partners.com. Over $30 \%$ of adults in Europe and North America willing to try cannabis infused drinks. 2020. Available at: https://prohibitionpartners. com/2020/08/11/over-30-percent-ofadults-in-europe-and-north-americawilling-to-try-infused-beverages/. Last accessed: December 2020.

22. Food Standards Agency. Cannabidiol (CBD) guidance. Available at: https:// ec.europa.eu/food/safety/novel food/catalogue/search/public/index. cfm. Last accessed: December 2020.

23. Open Access Government. EU crackdown: novel food regulation of CBD. 2020. Available at: https://www. openaccessgovernment.org/eu-novelfood-regulation-cbd/74422/. Last accessed: December 2020.

24. Cristino $L$ et al. Cannabinoids and the expanded endocannabinoid system in neurological disorders. Nat Rev Neurol. 2020;16(1):9-29.

25. European Monitoring Centre for Drugs and Drug Addiction. Cannabis legislation in Europe: an overview. 2018. Available at: http://www. emcdda.europa.eu/system/files/ publications/4135/TD0217210ENN. pdf. Last accessed: December 2020

26. World Health Organization. Cannabis. Available at: https://www.who.int/ substance_abuse/facts/cannabis/en/. Last accessed: December 2020.

27. International Drug Policy Consortium (IDPC). Aguilar S et al. Medicinal cannabis policies and practices around the world. 2018. Available at: http://fileserver.idpc.net/library/ Medicinal\%20cannabis\%20briefing ENG FINAL.PDF. Last accessed: December 2020

28. Healthline.com. Raypole C. A simple guide to the endocannabinoid system. 2019. Available at: https:// www.healthline.com/health/ endocannabinoid-system. Last accessed: December 2020.

29. Bradley.com. Steineker W, Wright JW Jr. USDA hemp announcement offers clarity, cause for concern for some. 2019. Available at: https:// www.bradley.com/insights/ publications/2019/05/usda-hempannouncement-offers-clarity-causefor-concern-for-some. Last accessed: July 2020.

30. Google Trends. https://trends.google. com/. Last accessed: December 2020.

31. Google search. https://www.google com/. Last accessed: December
32. Nature. Eisenstein $M$. The reality behind cannabidiol's medical hype. 2019. Available at: https://www. nature.com/articles/d41586-01902524-5. Last accessed: December 2020.

33. European Monitoring Centre for Drugs and Drug Addiction. WHO recommends rescheduling of cannabis. 2019. Available at: http:// www.emcdda.europa.eu/news/2019/ who-recommends-reschedulingof-cannabis_en. Last accessed: December 2020.

34. Bloomberg.com. Booming demand for CBD is making hemp the cannabis cash crop. 2019. Available at: https://www.bloomberg.com/ news/articles/2019-07-18/boomingdemand-for-cbd-is-making-hempthe-cannabis-cash-crop. Last accessed: December 2020.

35. World Population Review. com. Countries where weed is illegal. 2021. Available at: https:// worldpopulationreview.com/ countries/countries-where-weedis-illegal/. Last accessed: December 2020.

36. Forbes.com. Ledsom A. France's softening stance on cannabis opens huge economic potential. 2019. Available at: https://www.forbes. com/sites/alexledsom/2019/02/21/ frances-softening-stance-oncannabis-opens-up-huge-economicpotential/\#6c86fd1c576a. Last accessed: December 2020.

37. New frontier data.com. The EU CBD consumer report 2019 overview. Available at: https://newfrontierdata. com/product/the-eu-cbd-consumerreport/. Last accessed: December 2020

38. Drug science.org. Project Twenty21. Available at: https://drugscience.org uk/project-twenty21/. Last accessed: December 2020

39. Healtheuropa.eu. Maraver J. Kannabeira: standardised pharmaceutical grade cannabis and derivatives. 2019. Available at: https:// www.healtheuropa.eu/kannabeirastandardised-pharmaceutical-gradecannabis-and-derivatives/95158/. Last accessed: December 2020.

40. The Pharmaceutical Journal. Wickware C. NHS provides just 18 prescriptions for cannabisbased medical products in 2019 2020. Available at: https://www. pharmaceutical-journal.com/newsand-analysis/news/nhs-provides-just18-prescriptions-for-cannabis-basedmedical-products-in-2019/20208207. article. Last accessed: December 2020.

41. Chye $Y$ et al. The endocannabinoid system and cannabidiol's promise for the treatment of substance use disorder. Front Psychiatry. 2019;10(63). 
42. Pertwee RG et al. International Union of Basic and Clinical Pharmacology. LXXIX. Cannabinoid receptors and their ligands: beyond $\mathrm{CB}_{1}$ and $\mathrm{CB}_{2}$. Pharmacol Rev. 2010;62(4):588-631.

43. Niesink RJM, van Laar MW. Does cannabidiol protect against adverse psychological effects of THC? Front Psychiatry. 2013;16(4):130.

44. Lu HC, Mackie K. An introduction to the endogenous cannabinoid system. Biol Psychiatry. 2016;79(7):516-25.

45. Sensiseeds.com. Cannabinoid science 101: what is anandamide (AEA)? 2020. Available at: https://sensiseeds. com/en/blog/cannabinoid-science101-what-is-anandamide-aea/. Last accessed: December 2020.

46. Project CBD.org. How CBD works. Learn how CBD works with your body's endocannabinoid system. Available at: https://www.projectcbd. org/science/how-cbd-works. Last accessed: December 2020

47. Sallaberry CA, Astern L. The endocannabinoid system, our universal regulator. J Young Investig. 2018;34(5):48-55.

48. Arnold JC et al. The Yin and Yang of cannabis-induced psychosis: the Actions of $\Delta$ 9-tetrahydrocannabinol and cannabidiol in rodent models of schizophrenia. Curr Pharm Des. 2012:18(32):5113-30.

49. Schoedel KA et al. A randomized, double-blind, placebo-controlled, crossover study to evaluate the subjective abuse potential and cognitive effects of nabiximols oromucosal spray in subjects with a history of recreational cannabis use. Hum Psychopharmacol. 2011;26(3):224-36.

50. Bifulco M, Pisanti S. Medicinal use of cannabis in Europe. EMBO Reports. 2015;16(2):130-32

51. Whiting PF et al. Cannabinoids for medical use: a systematic review and meta-analysis. JAMA 2015;313(24):2456-73.

52. Abrams D. The therapeutic effects of cannabis and cannabinoids: an update from the National Academies of Sciences, Engineering and Medicine report. Eur J Int Med. 2018;49:7-11.

53. European Pharmaceutical Review. Cannabidiol-based treatment receives marketing approval from EMA. 2019. Available at: https://www. europeanpharmaceuticalreview. com/news/95506/marijuana-basedtreatment-approval-ema/. Last accessed: December 2020.

54. Krcevski-Skvarc $\mathrm{N}$ et al. Availability and approval of cannabis-based medicines for chronic pain management and palliative/ supportive care in Europe: a survey of the status in the chapters of the European Pain Federation. Eur J Pain 2018;22(3):440-54.

55. Shaare Zedek Medical Center. Aran A Cannabinoids for behavioral problems in children with ASD (CBA). Available at: https://clinicaltrials.gov/ct2/ show/-NCTO2956226?term=cannabi noid\&draw $=2 \&$ rank $=3$. Last accessed: December 2020

56. David Garcia Cinca. Effect of Cannabinoid (THC / CBD 50\%) on Hyperalgesia in Patients With Deep Endometriosis (EdomTHC). NCT03875261. https://clinicaltrials. gov/ct2/show/-NCT03875261?term =c annabinoid \&draw $=2 \& r a n k=4$.

57. Northwell Health. The use of cannabinoid patch for knee osteoarthritis. NCT04412837. https:// clinicaltrials.gov/ct2/show/record/NCT04412837?term=cannabinoid\&dr $\mathrm{aw}=2 \& \mathrm{rank}=19$.

58. Dolgin E. The bioengineering of cannabis. 2019. Available at: https:// www.nature.com/articles/d41586-019 02525-4. Last accessed: December 2020 .

59. Tramer MR et al. Cannabinoids for control of chemotherapy induced nausea and vomiting: quantitative systematic review. BMJ. 2001;323(7303):16-21.

60. Davis MP. Oral nabilone capsules in the treatment of chemotherapyinduced nausea and vomiting and pain. Exp Opin Investig Drugs. 2008;17(1):85-95.

61. Smith LA et al. Cannabinoids for nausea and vomiting in adults with cancer receiving chemotherapy. Cochrane Database Syst Rev. 2015;11:CD009464.

62. Fattore L, Fratta W. Beyond THC: the new generation of cannabinoid designer drugs. Front Behav Neurosci. 2011;5(60).

63. The Guardian. Marx RF. What happens when you try all the CBD products you can find? 2019 Available at: https://www.theguardian. com/lifeandstyle/2019/oct/17/whathappens-when-you-try-all-the-cbdproducts-you-can-find. Last accessed: December 2020.

64. Healtheuropa.eu. Porta H. The green rush for high-quality CBD products. 2019. Available at: https://www. healtheuropa.eu/high-quality-cbdproducts/92457/. Last accessed: December 2020.

65. Hazekamp A. The trouble with CBD oil. Med Cannabis Cannabinoids. 2018:1:65-72.

66. European Monitoring Centre for Drugs and Drug Addition (EMCDDA). Medical use of cannabis and cannabinoids: questions and answers for policymaking. 2018. Available at: https://www.emcdda.europa.eu/ publications/rapid-communications/ medical-use-of-cannabis-andcannabinoids-questions-and-answers for-policymaking en. Last accessed June 2021.

67. Lafaye $\mathrm{G}$ et al. Cannabis, cannabinoids, and health. Dialogues Clin Neurosci. 2017;19(3):309-16.

68. Leafly.com. Giraud C. Why does the high-THC flower dominate the cannabis market? 2019. Available at: https://www.leafly.com/news/ industry/high-thc-flower-dominatescannabis-market. Last accessed: December 2020.

69. NHS.UK. Cannabis: the facts. 2019 Available at: https://www.nhs.uk/ live-well/healthy-body/cannabis-thefacts/. Last accessed: May 2021.

70. Di Forti M et al. The contribution of cannabis use to variation in the incidence of psychotic disorder across Europe (EU-GEI): a multicentre case-control study. Lancet Psychiatry. 2019;6(5):427-36.

71. Filbey FM et al. Long-term effects of marijuana use on the brain. Proc Natl Acad Sci U S A. 2014;111(47):16913-18.

72. Gilman JM et al. Cannabis use is quantitatively associated with nucleus accumbens and amygdala abnormalities in young adult recreational users. J Neurosci. 2014;34(16) 5529-38.

73. Zettl UK et al. Evidence for the efficacy and effectiveness of THCCBD oromucosal spray in symptom management of patients with spasticity due to multiple sclerosis. Ther Adv Neurol Disord. 2016;9(1):930. 